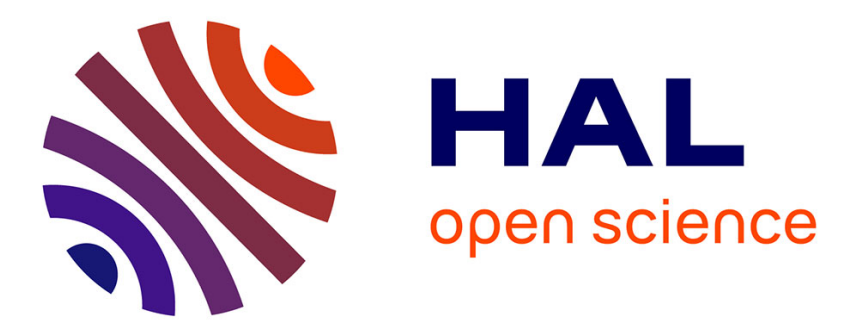

\title{
The Reaction of Dimethylalkynylaluminum Reagents with Trimethylsilyldiazomethane: Original Reactivity Leading to New $\alpha$-Silylated Alkynyl Hydrazones
}

Rahul Kumar, Serge Turcaud, Laurent Micouin

\section{- To cite this version:}

Rahul Kumar, Serge Turcaud, Laurent Micouin. The Reaction of Dimethylalkynylaluminum Reagents with Trimethylsilyldiazomethane: Original Reactivity Leading to New $\alpha$-Silylated Alkynyl Hydrazones. Organic Letters, 2014, 16 (23), pp.6192-6195. 10.1021/ol503113d . hal-02185384

\author{
HAL Id: hal-02185384 \\ https://hal.science/hal-02185384
}

Submitted on 16 Jul 2019

HAL is a multi-disciplinary open access archive for the deposit and dissemination of scientific research documents, whether they are published or not. The documents may come from teaching and research institutions in France or abroad, or from public or private research centers.
L'archive ouverte pluridisciplinaire HAL, est destinée au dépôt et à la diffusion de documents scientifiques de niveau recherche, publiés ou non, émanant des établissements d'enseignement et de recherche français ou étrangers, des laboratoires publics ou privés. 


\title{
The Reaction of Dimethylalkynylaluminum Reagents With Trimethylsilyldiazomethane: Original Reactivity Leading to New $\alpha$-Silylated Alkynyl Hydrazones
}

\author{
Rahul Kumar, Serge Turcaud and Laurent Micouin* \\ Laboratoire de Chimie et Biochimie et Pharmacologiques et Toxicologiques. UMR 8601 CNRS-Université Paris Descartes \\ Faculté des Sciences Fondamentales et Biomédicales, 45 rue des Saints Pères 75006 Paris, France.
}

Supporting Information Placeholder

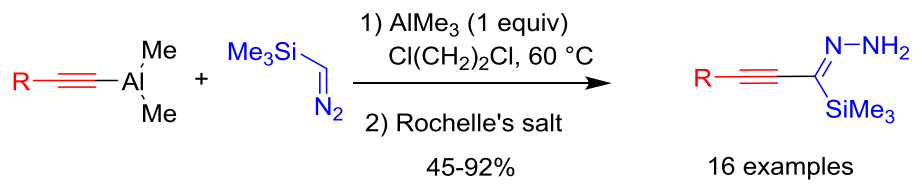

ABSTRACT: Trimethylsilyl (TMS) diazomethane does not react as an homologating reagent but as a C-electrophilic species with dimethylalkynylaluminum reagents. This unprecedented reactivity enables a simple access to unusual $\alpha$-silylated alkynyl hydrazones.

Diazoalkanes are useful synthetic reagents known to have a very diverse reactivity. They can act as free carbene or metal carbene precursors, leading to many important reactions such as insertions, cyclopropanations, 1,2-migrations, cross couplings and olefin metathesis. They can also behave as C-nucleophiles, 1,3-dipoles or $N$-electrophiles. ${ }^{1}$ This polyvalent reactivity can be illustrated by the reaction of diazoalkanes with organometallic compounds (Figure 1). Thus, transition metals are known to react with diazo compounds leading to metal carbenes of type A. ${ }^{2}$ Organomagnesium and lithium compounds have been described to react with the $\mathrm{N}$-terminal atom of diazoalkanes, leading to $\mathrm{N}$-substituted hydrazones $\mathbf{B} .^{3}$ More Lewis acidic, less nucleophilic compounds such as boranes ${ }^{4}$ or alanes ${ }^{5}$ are attacked by the C-terminus atom, leading to zwitterionic compounds $\mathbf{C}$ that can evolve by 1,2-migration reactions.

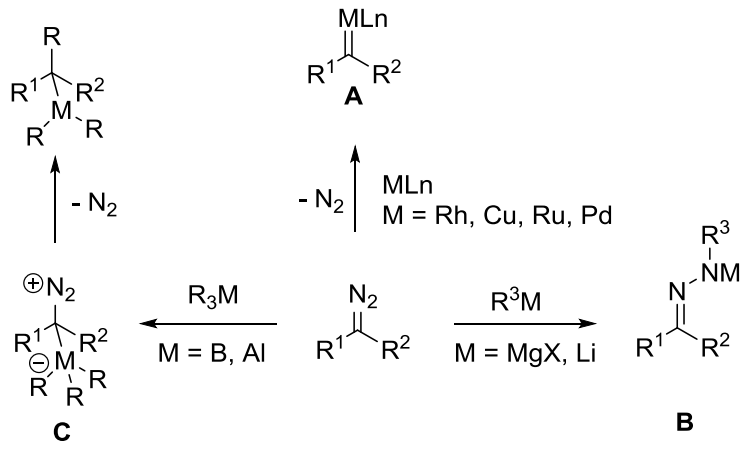

Figure 1. General reactivity of diazocompounds with organometallic reagents

Despite a few reports on the reaction of diazomethane with several organoaluminum compounds, the reaction of diazocompounds with this class of organometallic reagents has been surprisingly much less investigated than with their borane homologues. The reaction of alkyl, alkenyl or phenylaluminum reagents with diazomethane leads to intermediates of type $\mathrm{C}$ and eventually to homologated organoaluminum compounds under carefully controlled conditions to avoid the linear oligomerization (Aufbau) reaction. ${ }^{5}$ This reaction is strongly dependent on the Lewis acidity of the reagents. ${ }^{6}$

In our ongoing work on the reactivity of mixed dimethylalkynyl aluminum reagents, we have recently shown that these reagents can act as nucleophiles, ${ }^{7}$ but also formal dipolarophiles. ${ }^{8}$ We were therefore interested in investigating their reactivity with trimethylsilyldiazomethane (TMS diazomethane), as this diazo compound is known to behave as a dipole reagent with alkynes ${ }^{9}$ as well as a C-nucleophile with organoboron compounds, leading to intermediates of type $\mathbf{C}{ }^{10}$

Our first experiments with dimethylalkynylaluminum 1a did not afford any of the expected products, but led to the formation of $\alpha$-silylated hydrazone 2 a in $34 \%$ yield (Table 1 , entry 1 ). The unprecedented electrophilic behavior of TMS diazomethane and the uniqueness of the product prompted us to investigate this reaction further. A longer reaction time led to an improved yield of $53 \%$ (Table 1 , entry 2 ). Interestingly, the reaction was inhibited by the addition of one equivalent of triethylamine (Table 1, entry 3). ${ }^{\text {a }}$ On the contrary, addition of one equivalent of trimethylaluminum led to an improved chemical yield of $65 \%$ after 48 hours (Table 1, entry 4$).{ }^{11}$ Best conditions were obtained by heating the reaction mixture at 60 ${ }^{\circ} \mathrm{C}$ in 1,2- dichloroethane (DCE) for $24 \mathrm{~h}$, leading to compound $2 \mathrm{a}$ in $92 \%$ chemical yield (Table 1 , entry 7 ). 
Table 1. Optimization of the reaction conditions: solvent and additives $^{a}$

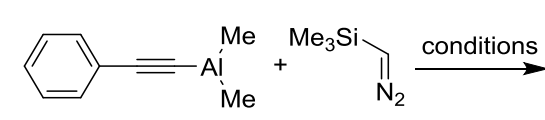

$1 a$

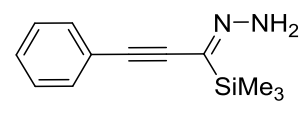

$2 a$

$\begin{array}{lllcll}\text { entry } & \text { solvent } & \begin{array}{l}\text { temp } \\ \left({ }^{\circ} \mathrm{C}\right)\end{array} & \text { additive } & \text { time (h) } & \begin{array}{l}\text { yield } \\ (\%)\end{array} \\ 1 & \text { Toluene } & 25 & - & 12 & 34 \\ 2 & \text { Toluene } & 25 & - & 60 & 53 \\ 3 & \text { Toluene } & 25 & \mathrm{Et}_{3} \mathrm{~N} & 48 & 0 \\ 4 & \text { Toluene } & 25 & \mathrm{AlMe}_{3} & 48 & 65 \\ 5 & \text { Toluene } & 60 & \mathrm{AlMe}_{3} & 48 & 78 \\ 6 & \mathrm{CH}_{2} \mathrm{Cl}_{2} & 40 & \mathrm{AlMe}_{3} & 24 & 71 \\ 7 & \mathrm{DCE}^{2} & 60 & \mathrm{AlMe}_{3} & 24 & 92\end{array}$

${ }^{a}$ Reaction conditions: 1 ( $1 \mathrm{mmol}$ in solvent), TMS diazomethane (2 $\mathrm{M}$ in $\left.\mathrm{Et}_{2} \mathrm{O}, 1.5 \mathrm{mmol}\right) .{ }^{b} 1$ equiv of $\mathrm{NEt}_{3}{ }^{c} 1$ equiv of $\mathrm{AlMe}_{3}(2 \mathrm{M}$ in toluene).

The scope of this reaction was then investigated using optimized conditions with a large variety of dimethylaluminum alkynides (Scheme 1). In all the cases, the corresponding silylated hydrazone was obtained as the sole isolated product in yields ranging from $45 \%$ to $92 \%$. The reaction tolerated both alkyl- $(2 \mathrm{~b}, 2 \mathrm{c})$ or heteroatom- (2f-h) substituted arylalkynyl groups, as well as heterocyclic $(2 \mathbf{i})$ or functional alkyl $(2 \mathrm{~m})$, alkenyl $(2 \mathrm{n})$ or alkynyl $(2 \mathrm{p})$ moieties.
Scheme 1. Scope of the reaction ${ }^{a}$
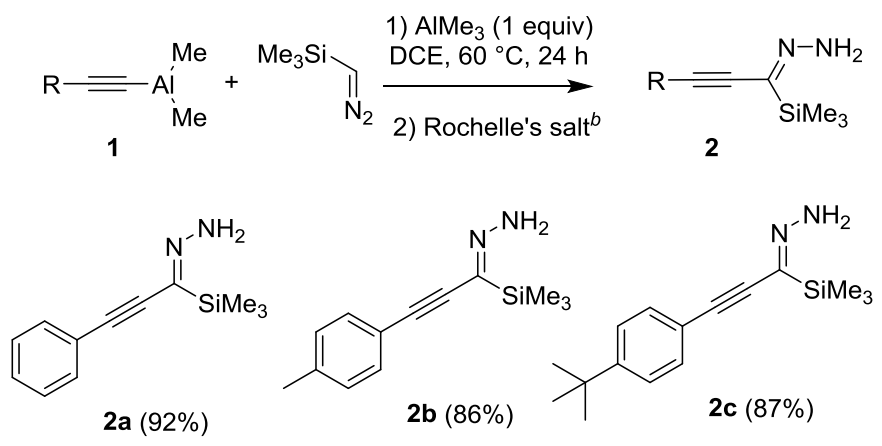<smiles>COC(C#Cc1ccc(N(C)C)cc1)=NN</smiles>

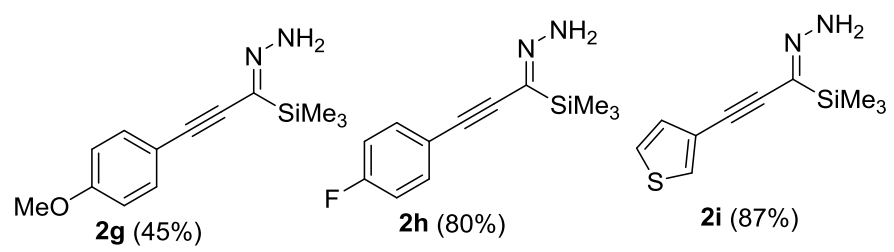

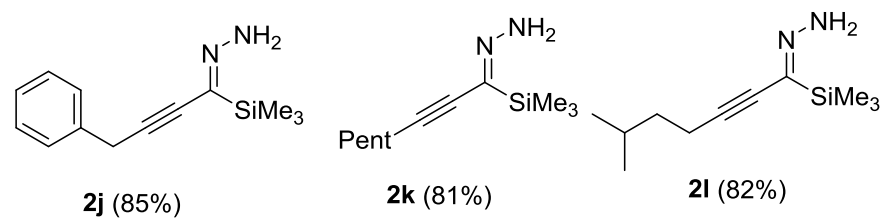

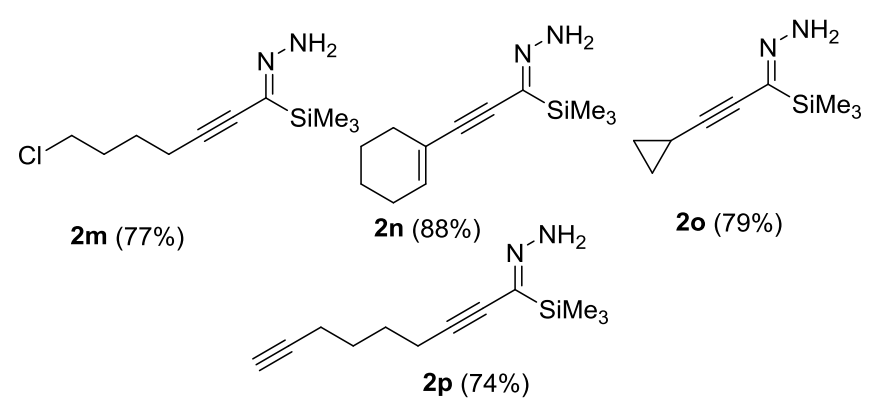

${ }^{a}$ All the dimethylalkynyl aluminum reagents have been prepared using a base-catalyzed terminal alumination of the corresponding alkynes. ${ }^{7 \mathrm{c}}$ All the reactions were quenched using a $2 \mathrm{M}$ aqueous solution of Rochelle's salt (also named Seignette's salt). This potassium sodium tartrate enables a neutral treatment of the reaction and breaks up emulsions generally obtained by standard hydrolysis of organoaluminum species.

A plausible mechanism for the formation of 2 is depicted in Scheme 2. For steric and electronic reasons, ${ }^{12}$ the reaction between 1 and TMS diazomethane does not lead to intermediate $\mathrm{C}$ but to $\mathrm{N}$-coordinated species $\mathrm{D}$ which is activated toward nucleophilic attack, leading to intermediate $\mathrm{E}^{13}$ Isomerization before (intermediate $\mathrm{F}$ ) or during the acidic quench of the reaction results in the formation of compound 2 . 
Scheme 2. Proposed mechanism for the formation of silylated hydrazones

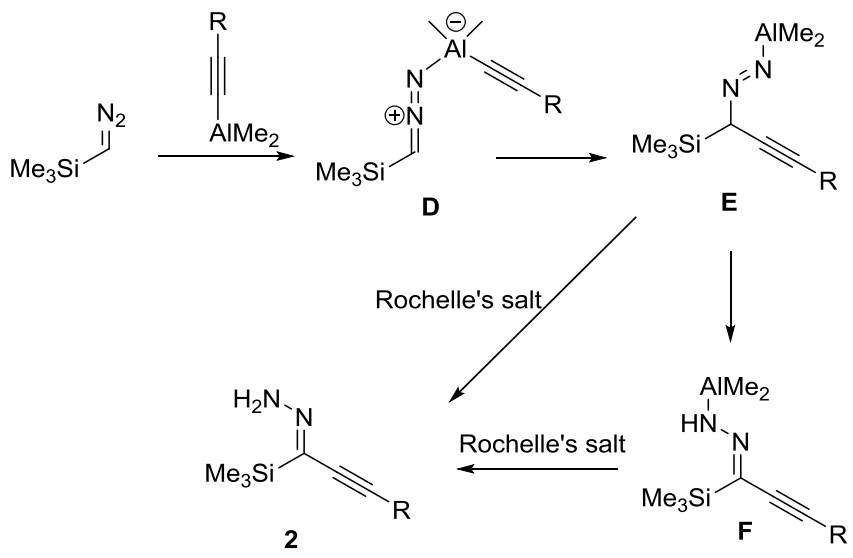

Although acylsilanes are well known reagents, ${ }^{14}$ the corresponding hydrazone derivatives are much less documented. ${ }^{15}$ To the best of our knowledge, unsubstituted $\alpha$-silylated alkynyl hydrazones have never been described and their reactivity is unknown. A few synthetic applications of these species have been investigated.

A simple transformation of silylated alkynylhydrazones is the protodesilylation. These compounds proved to be quite sensitive to acid traces (they have to be purified on alumina), and can easily lead to the corresponding unsubstituted hydrazone 3 (Scheme 3). The preparation of 3 is not obvious since the condensation of hydrazine with 3-phenylpropiolaldehyde is hampered by the competitive formation of pyrazole. ${ }^{16}$

Scheme 3. Protodesilylation of compound 2a

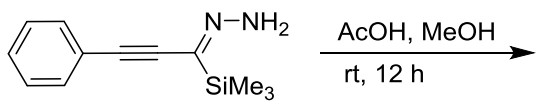

2a

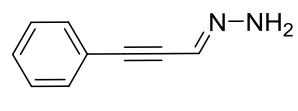

$3(75 \%)$
Compound 3 can serve as interesting starting material for new transformations, such as the intramolecular hydrazinoalumination, leading to substituted $\mathrm{N}$-H-pyrazoles 5-8 after reaction with electrophiles (Scheme 4). ${ }^{17}$

More interestingly, compound 2 a can lead to the corresponding diazo 9 under oxidative conditions (Scheme 5). ${ }^{15}$ Isolation and characterization of compound 9 in pure form proved to be difficult, but its formation was confirmed by its in situ reaction with benzoic acid, ${ }^{18}$ leading to the $\alpha$-benzoyl propargyl silane 10 in $78 \%$ overall isolated yield. ${ }^{19}$ This example clearly outlines the potential of silylated alkynylhydrazones to be valuable precursors of $\alpha$-alkynyl $\alpha$-trimethylsilyl diazomethane using a simple experimental procedure. Such diazo compounds have never been described, and their reactivity has to be investigated. ${ }^{20}$
Scheme 4. Synthesis of NH-pyrazoles from 3

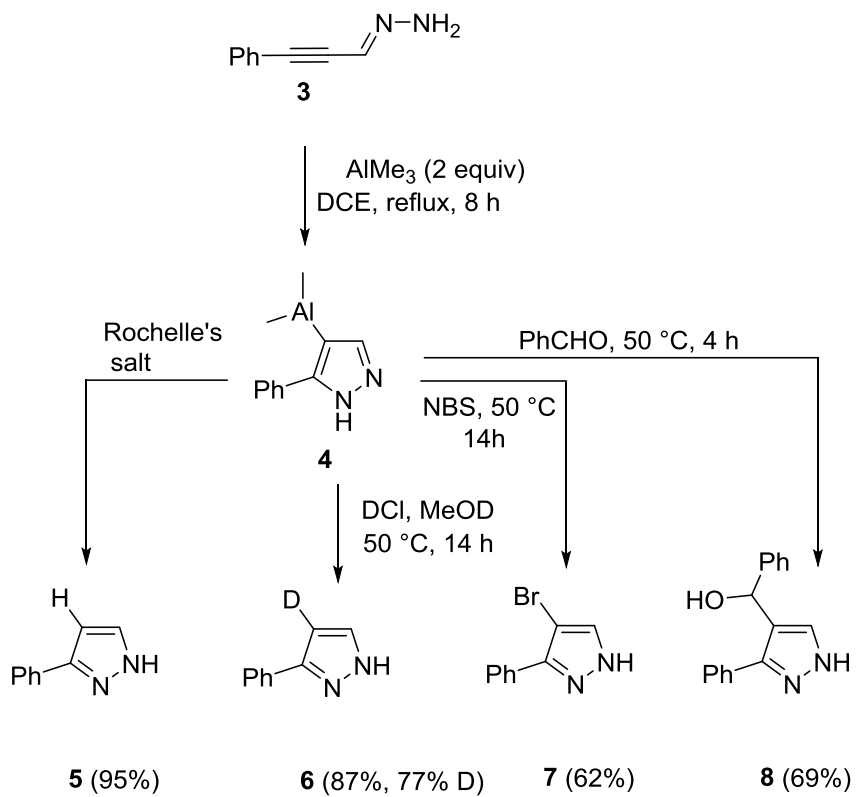

Scheme 5. Synthesis of TMS diazoalkyne 9 and reaction with benzoic acid 2a $\underset{0{ }^{\circ} \mathrm{C} \text { to rt, } 12 \mathrm{~h}}{\stackrel{\mathrm{MnO}_{2}, \mathrm{CH}_{2} \mathrm{Cl}_{2}}{\longrightarrow}}$
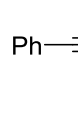

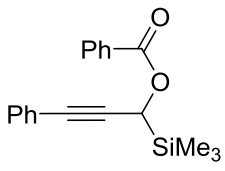

$10(78 \%$ from $2 a)$
In summary, we have reported a new reactivity of TMS diazomethane with dialkylalkynylaluminum reagents. This unprecedented reactivity enables the preparation of silylated alkynylhydrazones, a new class of reagents. Preliminary reactivity studies revealed that these compounds can be useful precursors to alkynylhydrazones, pyrazoles and $\alpha$-benzoyl propargyl silanes. We have also shown that starting from TMS diazomethane, it is possible to access TMS alkynyldiazomethane in only two steps. This new synthetic pathway enables the preparation of a new class of diazo compounds, whose reactivity is currently under investigation in our laboratory.

\section{ASSOCIATED CONTENT}

\section{Supporting Information}

General experimental procedures and analytical data for all new compounds. This material is available free of charge via the Internet at http://pubs.acs.org.

\section{AUTHOR INFORMATION}

\section{Corresponding Author}

*Laurent.micouin@parisdescartes.fr

\section{ACKNOWLEDGMENT}


Financial support from ANR (ANR blanc TribAl), CNRS and University Paris Descartes is acknowledged.

\section{REFERENCES}

(1) a) Eistert, B.; Regitz, M.; Heck, G.; Schwall, H. Methoden Org. Chem. (Houben-Weyl) 4th ed. 1952-, Vol.E 14b, pp 961-1371; b) Tomilov, Y. V.; Dokichev, V. A.; Dzhemilev, U. M.; Nefedov, O. M. Russ. Chem. Rev. 1993, 62, 799; c) Ye, T.; McKervey M. A. Chem. Rev. 1994, 94, 1091; d) Padwa, A.; Austin, D. J. Angew. Chem., Int. Ed. Engl. 1994, 33, 1797; e) Padwa, A.; Weingarten, M. D. Chem. Rev. 1996, 96, 223; f) Doyle, M. P.; Forbes, D. C. Chem. Rev. 1998, 98, 911; g) Zhang, Z.; Wang, J. Tetrahedron 2008, 64, 6577; h) Davies, H. M. L.; Manning, J. R. Nature 2008, 451, 417.

(2) a) Xiao, Q.; Zhang, Y.; Wang, J. Acc. Chem. Res. 2013, 46, 236; b) Liu, Z.; Wang, J. J. Org. Chem. 2013, 78, 10024 and ref. 1b-h.

(3) Coleman, G. H.; Gilman, H.; Adams, C. E.; Pratt, P. E. J. Org. Chem. 1938, 3, 99.

(4) Li, H.; Zhang, Y.; Wang, J. Synthesis 2013, 45, 3090.

(5) a) Hoberg, H. Ann. Chem. 1962, 656, 1; b) Hoberg, H. Angew. Chem. 1965, 77, 1084; c) Hoberg, H.; Ann. Chem. 1966, 695, 1.; d) Pauson, P. L.; Williams, B. J. J. Chem. Soc. 1961, 4162; e) Heydt, H. in Science of Synthesis, Houben-Weyl Methods of Molecular Transformations; Padwa, A. Ed.; Georg Thieme Verlag: Stuttgart, 2004; Vol 27, pp 843-935.

(6) Saegusa, T.; Tomita, S.; Ueshima, T. J. Organometal. Chem. 1967, 10, 360.

(7) a) Feuvrie, C.; Blanchet, J.; Bonin, M.; Micouin, L. Org. Lett. 2004, 6, 2333; b) Wang, B.; Bonin, M.; Micouin, L. J. Org. Chem. 2005, 70, 6126; c) Zhou, Y.; Lecourt, T.; Micouin, L. Adv. Synth. Catal. 2009, 351, 2595; d) Jackowski, O.; Lecourt, T.; Micouin, L. Org. Lett., 2011, 13, 5664.

(8) Zhou, Y.; Lecourt, T.; Micouin, L. Angew. Chem., Int. Ed. 2010, 49, 2607. (9) a) Bassindale, A. R.; Brook, A. G. Can. J. Chem. 1974, 52, 3474; b) Mish, M. R.; Guerra, F. M.; Carreira, E. M. J. Am. Chem. Soc. 1997, 119, 8379; c) Kanemasa, S.; Kanai, T. J. Am. Chem. Soc. 2000, 122, 10710; d) GonzálezNogal, A. M.; Calle, M.; Cuadrado, P.; Valero, R. Tetrahedron 2007, 63, 224 e) Vuluga, D.; Legros, J.; Crousse, B.; Bonnet-Delpon, D. Green Chem. 2009, 11, 156.

(10) a) Bai, J.; Shea, K. J. Macromol. Rapid Commun 2006, 27, 1223; b) Goddard, J.-P.; Le Gall, T.; Mioskowski, C. Org. Lett. 2000, 2, 1455; c) Neu, R. C.; Stephan, D. W. Organometallics 2012, 31, 46.

(11) The beneficial effect of trimethylaluminum is not clear at this stage. As the TMS diazomethane is used as a $2 \mathrm{M}$ ether solution, we believe that ether can coordinate aluminium acetylides and slow down the reaction. The addition of a better Lewis acid such as trimethylaluminum can minimize this deactivating pathway, leading to an improved reaction rate. The organoaluminum-promoted ketone homologation with diazoalkanes reported by $\mathrm{Ya}$ mamoto illustrates the inhibiting effect of a Lewis base on the reaction between organoaluminum reagents and diazoalkanes. Maruoka, K.; Conception, A. B.; Yamamoto, H. J. Org. Chem. 1995, 59, 4725.

(12) The HOMO is lower in energy for TMS diazomethane than for diazomethane (ref 9a) and steric hindrance is known to disfavor the formation of intermediate C (ref 10a).

(13) The reaction of TMS diazomethane with dialanes has been reported to occur by the insertion of the terminal nitrogen atom into the aluminumaluminum bond: Uhl, W.; Hannemann, F. Eur. J. Inorg. Chem. 1999, 201.

(14) Zhang, H.-J.; Priebbenow, D. L.; Bolm C. Chem. Soc. Rev. 2013, 42, 8540.

(15) Kaufmann, K. D.; Auräth, B.; Träger, P.; Rühlmann, K. Tetrahedron Lett. 1968, 48, 4973.

(16) Eremeev, A. V.; Tikhomirov, D. A.; Tyusheva, V. A.; Liepin'sh E. E. Chem. Heterocycl. Compd. 1978, 14, 612.

(17) For reactivity studies of trimethylaluminum and hydrazines, see: Uhl, W.; Hagemeir, E.; Layh, M.; Rezaeirad, B.; Kösters, J.; Würthwein, E.-U.; Ghavtadze, N.; Massa, W. Eur. J. Inorg. Chem. 2011, 1733.

(18) Hancock, C. K.; Gilby Jr., R. F.; Westmoreland, J. S. J. Am. Chem. Soc. 1957, 79, 1917.

(19) For a recent alternative preparation of $\alpha$-hydroxypropargyl silanes and their great synthetic potential, see: Smirnov, P.; Mathew, J.; Nijs, A.; Katan,
E.; Karni, M.; Bolm, C.; Apeloig, Y.; Marek, I. Angew. Chem. Int. Ed. 2013, $125,13962$.

(20) For the synthesis of diazoalkynes as triplet carbenes precursors, see: a) Bowling, N. P.; Halter, R. J.; Hodges, J. A.; Seburg, R. A.; Thomas, P. S.; Simmons, C. S.; Stanton, J. F.; McMahon, R. J. J. Am. Chem. Soc. 2006, 128, 3291; b) Noro, M.; Masuda, T.; Ichimura, A. S.; Koga, N.; Iwamura, H. J. Am. Chem. Soc. 1994, 116, 6179. For the preparation of diazoalkynes and their use in homologation reactions, see: a) Moebius, D. C.; Kingsbury, J. S. J. Am. Chem. Soc. 2009, 131, 878; b) Wommack, A. J.; Moebius, D. C.; Travis, A. L.; Kingsbury, J. S. Org. Lett. 2009, 11, 3202. 
